\title{
Prehospital preterm difficult breech delivery - two case reports
}

BY DUBRAVKO HABEK

\section{Abstract}

We report on two cases of prehospital initiated precipitated preterm deliveries with breech presentation, which were completed at the hospital. Case 1 involved a precipitated breech delivery in a multipara, and case 2 an unrecognizeddizygotic (diamniotic, dichorionic) twin pregnancy, with precipitated preterm breech delivery of the first twin, in a multipara.

Key words: breech delivery, emergency

\section{Introduction}

Prehospital deliveries are associated with a higher rate of complications due mostly to obstetric hemorrhage, shoulder dystocia, precipitated labor and breech malpresentation with complications. Breech presentation has a prevalence of $3 \%-4 \%$, with a significantly higher rate in preterm deliveries. It is also more frequently encountered in multiparae, malformed and premature neonates, thus the labor being burdened with potential complications (retained hands, head deflection, umbilical prolapse, perinatal asphyxia, cervical spasm, etc.). Therefore, breech presentation has recently been increasingly managed by cesarean section, although no difference in perinatal outcome was found in selected cases 
between cesarean section and vaginal delivery. $(1,2)$

We report on two cases of prehospitally initiated precipitated preterm deliveries with breech presentation, which were completed at the hospital.

\section{Case presentation 1}

A 34-year-old housewife in her $35^{\text {th }}$ week of gestation called an ambulance for labor pains and amniotic sac rupture. She had already given birth to four healthy children, had no comorbidities, and the course of the current pregnancy was normal. The ambulance arrived in ten minutes of her call and the crew found the woman lying on the bed with the neonate in breech presentation expelled up to the head. The physician and medical technician were unable to release the head and complete the delivery; therefore, they immediately transferred the woman to the ambulance and transported her to the hospital, at the same time calling the hospital for the obstetric team to wait for her at the hospital emergency department. On arrival, the obstetrician found the preterm neonate's body in breech presentation, without umbilical cord pulsations; he released the head using the Mauriceau-Levret-Veit-Smellie maneuver and delivered a preterm female newborn without vital signs.

Cardiopulmonary resuscitation was immediately initiated, however, after 30 minutes of resuscitation, death due to asphyxia (Apgar score $0,0,0$ ) was diagnosed. Birth anthropometry was $2400 \mathrm{~g} / 43 \mathrm{~cm}$. Autopsy revealed acute asphyxial events (numerous ecchymoses on serous membranes with cerebral and pulmonary edema). The puerperal course was uneventful, with antibiosis and thromboprophylaxis given. The woman was discharged from the hospital in good health.

\section{Case presentation 2}

In a 38-year-old divorced waitress, labor started in her apartment with abrupt onset of labor pains and amniotic sac rupture. She had delivered two children 18 and 20 years before. Her current pregnancy was not being monitored. She lived in very poor social conditions and was a 
chronic smoker. She said that the neonate's feet were delivered immediately after amniotic sac rupture, and she pulled them to complete delivery, however, she could not do it and told her son to call an ambulance. The ambulance came in ten minutes and the crew found the woman squatting and pulling the neonate's feet. The physician and medical technician transferred her immediately to the ambulance and tried to deliver the baby several times, without success. There were no umbilical cord pulsations. The woman was transported to the University Department of Gynecology Maternity Ward, where the obstetrician on duty found the neonate delivered up to the hands with no umbilical cord pulsations; he performed the Müller and Mauriceau-Levret-Veit-Smellie maneuvers and delivered a female preterm without vital signs. The neonatologist initiated resuscitation immediately (Apgar score $0,2,5$ ) and assessed the premature's age at 32/33 weeks; birth anthropometry was $1930 \mathrm{~g} / 47 \mathrm{~cm}$. The baby was decerebrated, kept on mechanical ventilation and died on postnatal day five from multiorgan failure. Following delivery, the woman's abdomen was still enlarged and another fetus (i.e. twin pregnancy) was diagnosed by ultrasound and examination, also in breech presentation. The amniotic sac was broken and a live preterm, $2170 \mathrm{~g} / 45 \mathrm{~cm}$, Apgar score 8, 9, was delivered by manual extraction by the feet. The puerperal course was uneventful, with antibiosis and thromboprophylaxis given. The woman was discharged from hospital, together with her second healthy twin.

\section{Discussion}

Breech delivery is a rarely described emergency in prehospital conditions or emergency non-obstetric services. The possible complications that mostly occur due to precipitated labor carry a risk of increased perinatal morbidity and mortality. (3) Although the majority of prehospital deliveries are completed without undesired events, some precipitated and difficult deliveries, in particular those with malpresentation, shoulder dystocia, breech presentation and uterine inversion, are associated with a high risk of complications and require the skills of emergency physicians and other staff to solve particular intrapartal complications using obstetric operations and manual aids. (4-6) The small number of reports 
on these issues suggest the need for continuous education and skills in managing obstetric and gynecologic emergencies in the prehospital setting and emergency department where there is no obstetrician. Emphasis should be put on the indications, contraindications, techniques and potential complications related to particular life-threatening emergency conditions. (4-7)

Intrapartal complications in breech delivery are more common in incomplete breech presentation and footling presentation, in particular with head deflection and retained hands with consequential asphyxia and possible neonatal death. In breech presentation, spontaneous delivery is recommended because it is associated with the lowest rate of peripartum, short-term and long-term complications, whereas manual aids and complicated breech presentations (incomplete, footling) have been shown to correlate directly with poor perinatal outcome. (8) In both cases presented, retention of fetal hands and deflected head resulted in a lethal outcome. Case 1 involved a precipitated breech delivery in a multipara, and case 2 a dizygotic (diamniotic, dichorionic) twin pregnancy, with precipitated preterm breech delivery of the first twin, in a multipara.

Although rare, the possibility of prehospital breech/footling delivery, associated with high mortality, requires a skilled and educated emergency medicine team in managing the possible intrapartum complications of this high risk delivery, risk identification with potential errors, strictly following clinical practice guidelines $(4,7)$ and facing consequential medicolegal implications.

\section{References}

1. Habek D. Minimally assisted breech delivery. Gynaecol Perinatol 2009;18:17-22.

2. Brunette DD, Sterner SP. Prehospital and emergency department delivery: a review of eight years experience. Ann Emerg Med 1989;18:1116-8.

3. Givens ML, Westermyer R. Term incomplete breech delivery in an ambulance: a case report. J Emerg Med 2005;28:301-3.

4. Maslowitz S, Barkai G, Lessing BJ, Ziv A, Many A. Recurrent obstetric 
management mistakes identified by simulation. Obstet Gynecol 2007;1296-1300.

5. Silver DW, Sabatino F. Precipitous and difficult deliveries. Emerg Med Clin North Am 2012;30:961-75.

6. Mercado J, Brea I,Mendez B, Quinones H, Rodriquez D. Critical obstetric and gynecologic procedures in the emergency depatment. Emerg Clin North Am 2013;31:207-36.

7. Jan H, Guimicheva B, Gosh S, Hamid R, Penna L, Sarris I. Evaluation of healthcare professionals' understanding of eponymous maneuvers and mnemonics in emergency obstetric care provision. Int $J$ Gynaecol Obstet 2014;228.-31.

8. Vranješ M, Habek D. Perinatal outcome in breech presentation depending on mode of vaginal delivery. Fetal Diagn Ther 2008;23:54-9.

Correspodence adress:

Dubravko Habek

University Department of Obstetrics and Gynecology

University Hospital „Sveti Duh“ Zagreb

Sveti Duh 64 Street, 10000 Zagreb, Croatia

Fax: 0038513745534

E-mail: dubravko.habek@os.t-com.hr

Article printed from Signa Vitae: http://www.signavitae.com

URL to article: http://www.signavitae.com/2015/12/prehospitalpreterm-difficult-breech-delivery-two-case-reports/

Copyright (C) 2015 Signa Vitae. All rights reserved. 